exposure on autoimmune diseases like inflammatory bowel disease and type one diabetes have also been suggested. The impact of timing of organic exposure as well as the relation between occupational and environmental exposure to organic dust (levels as well as diversity of microorganisms) and the human microbiome will be discussed as possible explanations for the dual effects of organic dust exposure.

\section{3b ASTHMA IN SERICULTURE WORKERS DUE TO ORGANIC DUST EXPOSURE}

S Chandrasekar. Private Sector, Bangalore, India

10.1136/oemed-2018-ICOHabstracts. 1342

Occupational Asthma in employees is attributable to exposure to biological or inorganic agents at workplace. Sericulture is an agro-cottage industry under informal sector. Silk manufacturing involves several steps. Workers are exposed to aerosols generated when silkworm cocoons are placed in boiling water to dissolve 'sericin' from outer layer. Silk thread reeled from cocoon is rolled, twisted into yarn and dyed before weaving. Workers employed in grainages where cocoons are stored and in cocoon trading centres are exposed to epithelial dust from silkworm moths and cocoons. Workers in farms producing mulberry leaves for silkworm rearing centres and dyeing units are also at risk of developing asthma as they are exposed to pesticides, disinfectants and chemical dyes. Previous studies showed that some sericulture workers develop sensitisation to silkworm allergens over a period. Objective of this study was to detect prevalence of asthma among sericulture workers, as many cases of asthma were observed in places where there are many sericulture industries in South India. 100 workers engaged in sericulture for more than 10 years and 100 persons from general population as control, who volunteered for this study, were enrolled. Clinical history and examination of enrolled persons was done. All participants underwent pulmonary function test and asthmatics among them underwent bronchial reversibility test. Results showed $14 \%$ of workers had occupational asthma and in control group 6\% had allergic bronchitis. Mechanisation and installation of barriers to prevent manual handling and aerosol exposure is recommended, but not possible being a cottage industry with many small filature units. Quitting job is not practical due to workers financial status. Hence awareness programmes on prevention, personal protective equipments and early treatment is required. In conclusion, sericulture workers are at risk of developing asthma and continued exposure to allergens can progress to chronic obstructive pulmonary disease in some workers.

\section{C DETERMINANTS FOR ASTHMA IN FARMERS WITH SPECIAL REFERENCE TO ODTS (ORGANIC DUST TOXIC SYNDROME)}

A Rask-Andersen. Department of Medical Sciences, Occupational and Environmental Medicine, Uppsala University, Uppsala, Sweden

10.1136/oemed-2018-ICOHabstracts. 1343

Organic dust toxic syndrome (ODTS) is an acute, febrile, noninfectious, flu-like, short-term reaction that can be seen in a range of situations after inhalation of substances that give rise to an inflammatory reaction in the lungs. There are anecdotical reports suggesting that ODTS is a risk factor for asthma in farmers. In a cross-sectional study, questionnaires were mailed to farmers in middle Sweden and southern Sweden. Sixty percent of the farmers (1004 men and 129 women) responded to the questionnaire. The mean age was 51 years. Nine percent were smokers and 24 percent ex-smokers. The female farmers had a significantly higher prevalence of doctordiagnosed asthma compared to the males, 8.3 percent compared to 4.5 percent $(\mathrm{p}<0.05)$ and worked significantly more often in all productions involving animals. Regression analysis of male farmers showed that ODTS was a risk factor for respiratory symptoms such as wheeze, work related wheeze, nightly breathlessness and chronic bronchitis. Long time in agricultural work was another risk factor for wheeze, work related wheeze, doctor-diagnosed asthma and chronic bronchitis. Swine farming was a risk factor for chronic bronchitis. Possible mechanism behind these findings and prevention strategies will be discussed.

\section{3d AGRICULTURAL RISK FACTORS FOR LYMPHOMA - CONTACT WITH LIVESTOCK AND EXPOSURE TO ORGANIC DUST}

P Cocco, G Satta. Department of Medical Sciences and Public Health, University of Cagliari, Cagliari, Italy

\subsection{6/oemed-2018-ICOHabstracts. 1344}

Introduction Farming occupations have been reported at risk of developing non Hodgkin lymphoma. Within the EPILYMPH multicentre European case-control study on the aetiology of lymphoma, we explored the association of risk of the major lymphoma subtypes with exposure to specific classes of pesticides, contact with livestock, and exposure to organic dust.

Methods In 1998-2003, 2348 cases of lymphoma (all subtypes), and 2462 controls participated in the EPILYMPH casecontrol study in several centres six European countries. A detailed occupational history was collected in cases and controls. Information on contact with breeding animals, exposure to five organic dusts, and to specific classes of pesticides was obtained through personal interviews. Local agronomists and occupational experts assessed likelihood, frequency and intensity of specific exposures based on the questionnaire information. Risk of the major lymphoma subtypes associated with contact with the most frequently represented species of livestock, organic dusts, and classes of pesticides was calculated with unconditional logistic regression analysis adjusting by age, gender, education, and centre.

Result Exposure to organophosphate insecticides was significantly associated with an increase in risk of chronic lymphocytic leukaemia; risk of DLBCL, was significantly lower amongst subjects who started occupational contact with any species of livestock before or at age $12(\mathrm{OR}=0.5$, 95\% CI: 0.2 to 0.9 ), but not at older ages. A significant heterogeneity in risk of B cell lymphoma by age at first contact was detected for contact with cattle, poultry and swine. We did not find an association with exposure to any of the organic dust exposures.

Discussion Agricultural exposures are numerous, and difficult to disentangle; also, the use of agrochemicals varies with time, 